University of New Orleans

ScholarWorks@UNO

$12-15-1983$

\title{
Pseudo-Brewster and second-Brewster angles of an absorbing substrate coated by a transparent thin film
}

\author{
R. M.A. Azzam \\ University of New Orleans, razzam@uno.edu \\ T F. Thonn
}

Follow this and additional works at: https://scholarworks.uno.edu/ee_facpubs

Part of the Electrical and Electronics Commons, and the Optics Commons

\section{Recommended Citation}

R. M. A. Azzam and T. F. Thonn, "Pseudo-Brewster and second-Brewster angles of an absorbing substrate coated by a transparent thin film," Appl. Opt. 22, 4155-4165 (1983)

This Article is brought to you for free and open access by the Department of Electrical Engineering at ScholarWorks@UNO. It has been accepted for inclusion in Electrical Engineering Faculty Publications by an authorized administrator of ScholarWorks@UNO. For more information, please contact scholarworks@uno.edu. 


\title{
Pseudo-Brewster and second-Brewster angles of an absorbing substrate coated by a transparent thin film
}

\author{
R. M. A. Azzam and T. F. Thonn
}

\begin{abstract}
The pseudo-Brewster angle of minimum reflectance for the $p$ polarization, the corresponding angle for the $s$ polarization, and the second-Brewster angle of minimum ratio of the $p$ and $s$ reflectances are all determined as functions of the thickness of a transparent film coating an absorbing substrate by numerical solution of the exact equations that govern such angles of the form $\operatorname{Re}\left(Z^{\prime} / Z\right)=0$, where $Z=R_{p}, R_{s}$, or $\rho$ represent the complex amplitude-reflection coefficients for the $p$ and $s$ polarizations and their ratio $\left(\rho=R_{p} / R_{s}\right)$, respectively, and $Z^{\prime}$ is the angle-of-incidence derivative of $Z$. Results that show these angles and their associated reflectance and reflectance-ratio minima are presented for the $\mathrm{SiO}_{2}-\mathrm{Si}$ film-substrate system at wavelength $\lambda=0.6328 \mu \mathrm{m}$ and film thickness of up to four periods $(\simeq 1.2 \mu \mathrm{m})$. Applications of these results are proposed in film-thickness measurement and control.
\end{abstract}

\section{Introduction}

When parallel $(p)$-polarized monochromatic light (or any other electromagnetic radiation) is obliquely reflected at the planar interface between isotropic transparent and absorbing media, the reflected intensity reaches a minimum at the so-called pseudo-Brewster angle $\phi_{p \mathrm{~B}}$. For perpendicularly $(s)$-polarized light, the interface reflectance increases monotonically with angle of incidence $\phi$ between normal $(\phi=0)$ and grazing $\left(\phi=90^{\circ}\right)$ incidence. Modification of this basic behavior of the $p$ and $s$ amplitude reflectances $\left(\left|R_{p}\right|\right.$ and $\left.\left|R_{s}\right|\right)$ vs $\phi$, caused by the presence of a transparent thin film (an intermediate third phase) between the two media, was briefly discussed recently ${ }^{1}$ with particular reference to the air- $\mathrm{SiO}_{2}-\mathrm{Si}$ (ambient-film-substrate) system at the wavelength $\lambda=632.8 \mathrm{~nm}$. A most striking change noted was the disappearance of the oblique-incidence minimum of $\left|R_{p}\right|$ and the appearance of one for $\left|R_{s}\right|$ (i.e., a switch of the monotonic and nonmonotonic behavior of reflectance vs $\phi$ for the $p$ and $s$ polarizations) for certain thickness ranges within the first filmthickness period $(\lesssim \lambda / 2)$.

When the thickness $d$ of the transparent layer increases and becomes comparable to or greater than $\lambda$, both $\left|R_{p}\right|$ and $\left|R_{s}\right|$ are known to exhibit oscillatory behavior with $\phi$ with several extrema (minima and

The authors are with University of New Orleans, Department of Electrical Engineering, Lakefront, New Orleans, Louisiana 70148. Received 9 August 1983.

0003-6935/83/244155-11\$01.00/0.

(C) 1983 Optical Society of America. maxima) whose number generally increases with $d$. For example, Fig. 1 shows $\left|R_{p}\right|$ vs $\phi$ for $d=3 D_{90}$, where $D_{90}$ $=297.4 \mathrm{~nm}$ is the film-thickness period at $\phi=90^{\circ} . D_{\phi}$ at any $\phi$ is given by

$$
D_{\phi}=1 / 2 \lambda\left(N_{1}^{2}-N_{0}^{2} \sin ^{2} \phi\right)^{-1 / 2},
$$

where $N_{0}$ and $N_{1}$ are the refractive indices of the ambient and film, respectively. The oscillatory variation of reflectance with $\phi$ (such as that of Fig. 1) is the basis of the variable-angle monochromatic fringe observation (VAMFO) technique for film-thickness measurement. $^{2}$

In this paper, the pseudo-Brewster angle of absolute minimum $\left|R_{p}\right|, \phi_{p \mathrm{~B}}^{p}$, the corresponding angle for $\left|R_{s}\right|, \phi_{p \mathrm{~B}}^{s}$, and the so-called second-Brewster angle $\phi_{2 \mathrm{~B}}$ of absolute minimum reflectance ratio $|\rho|=\left|R_{p} / R_{s}\right|$ are all determined as functions of the film thickness $d$. (Results are also presented for other critical points.) For definiteness, we choose the air $\left(N_{0}=1\right)-\mathrm{SiO}_{2}\left(N_{1}\right.$ $=1.46)-\mathrm{Si}\left(N_{2}=3.85-j 0.02\right)$ system at $\lambda=632.8 \mathrm{~nm}$. Results for other film-substrate systems were also obtained but not included here.

\section{Finding the Critical Points of a Reflectance vs $\phi$ Curve}

For a given $d$, the angular $\phi$ position of a minimum or maximum of a function $|Z|(\phi)$ is determined by an iterative numerical solution ${ }^{3}$ of the equation

$$
\operatorname{Re}\left(\frac{1}{Z} \frac{\partial Z}{\partial \phi}\right)=0
$$

where the complex function $Z$ stands for $R_{p}, R_{s}$, or $\rho$. Expressions for these functions and their angle-ofincidence derivatives are given elsewhere ${ }^{4,5}$ and will not 


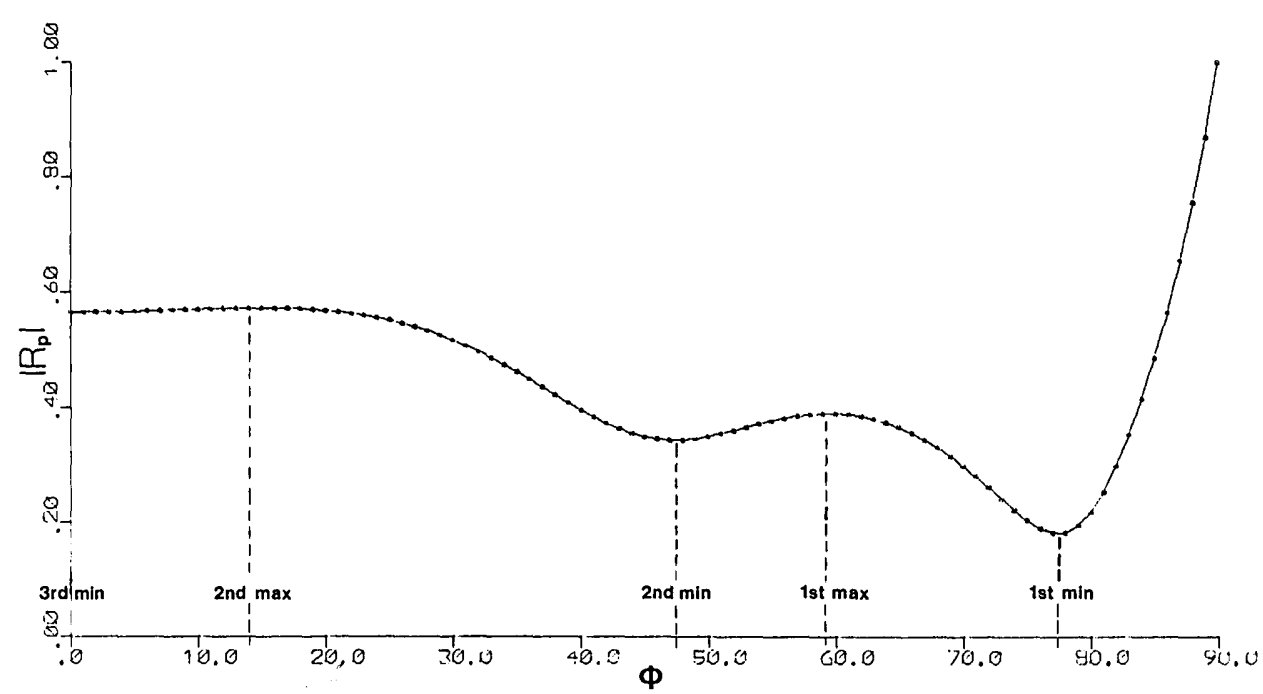

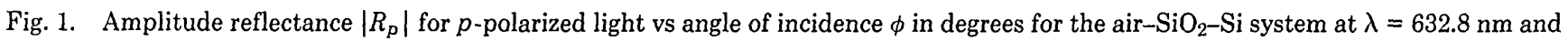
$\mathrm{SiO}_{2}$ film thickness of $d=3 D_{90}=892.3 \mathrm{~nm}$.

Table l. Crittcal Points of the $\left|R_{p}\right|$ vs $\phi$ Curve of Fig. $1(d=892.3 \mathrm{~nm})$

First min. First max. Second min. Second max. Third min.

\begin{tabular}{lrrrrr}
\hline$\phi(\mathrm{deg})$ & 77.424 & 59.213 & 47.580 & 14.032 & 0.000 \\
$\left|R_{p}\right|$ & 0.180 & 0.390 & 0.344 & 0.572 & 0.565 \\
\hline
\end{tabular}

be repeated here. Once $\phi$ that satisfies Eq. (2) is found, the minimum or maximum value of $|Z|$ is computed. Whether a critical point represents a maximum or minimum is easily determined without the need for a second differentiation as follows. When iteration is begun by decreasing $\phi$ from $90^{\circ}$, the first-to-be-encountered solution of Eq. (2) for $Z=R_{p}$ or $R_{s}$ is a minimum, and the nature of all other critical points (in the order of decreasing $\phi$ ) is, therefore, fixed. For $Z=\rho$, the first critical point under $90^{\circ}$ corresponds to a maximum or minimum depending upon whether $|\rho|>1$ or $<1$, respectively, because $|\rho|=1$ at $\phi=90^{\circ}$.

As an example, Table I summarizes the critical points of the $\left|R_{p}\right|$ vs $\phi$ curve of Fig. 1 for $d=3 D_{90}=892.3 \mathrm{~nm}$. This is the only table of this paper, as all other results will be presented only graphically.

\section{Pseudo-Brewster Angle and Associated Minimum Reflectance for the $p$ Polarization}

As has already been noted, for a given $d$ the curve of $\left|R_{p}\right|$ vs $\phi$ may exhibit multiple minima. A unique pseudo-Brewster angle for the $p$ polarization $\phi_{p \mathrm{~B}}^{p}$ is defined as that angle at which $\left|R_{p}\right|$ reaches its absolute (lowest) minimum value denoted by $\left|R_{p \text { min }}\right| . \phi_{p \mathrm{~B}}^{p}$ and $\left|R_{p \text { min }}\right|$ are both aperiodic functions of $d$, whereas $R_{p}$ is periodic with $d$ at a given $\phi$ with period given by Eq. (1).

Throughout this paper, we limit ourselves to four thickness periods,

$$
0 \leq d \leq 4 D_{90} \simeq 1.2 \mu \mathrm{m} .
$$

(Results can, of course, be similarly generated for any other thickness range of interest.) This range is divided into (at least) 400 points (i.e., 100 thickness values per period or $\simeq 3$-nm thickness steps), and for every $d$, Eq. (2) is solved for the particular angle(s) of interest.

Figure 2(a) shows $\phi_{p \mathrm{~B}}^{p}(d)$, and Fig. 2(b) gives the associated $\left|R_{p \min }\right|(d)$. Elimination of $d$ between Figs. 2(a) and (b) gives the direct relationship between $\left|R_{p \text { min }}\right|$ and $\phi_{p \mathrm{~B}}^{P}$ shown in Fig. 2(c). Points where the functions experience notable (or discontinuous) change are marked by $A, B, C \ldots$ These functions are rather elaborate, and their behavior could in no way have been foretold. Let us follow them at least within the first film-thickness period $(0 \leq d \leq 0.3 \mu \mathrm{m})$, which begins at $A$ and ends at $C^{\prime \prime}$. Point $A$ represents the bare $\mathrm{Si}$ substrate, where $\phi_{p \mathrm{~B}}^{p}=75.44^{\circ}$ and $\left|R_{p \min }\right|=0.0024$. As $d$ increases from 0 to $d_{B} \simeq 78 \mathrm{~nm}, \phi_{P \mathrm{~B}}^{p}$ drops (initially slowly then rapidly) to 0 , while $\left|R_{p \text { min }}\right|$ increases steeply from $\simeq 0$ to near a maximum $(\simeq 0.381)$. This rather sensitive variation of $\phi_{p \mathrm{~B}}^{p}$ and (or) $\left|R_{p \text { min }}\right|$ with $d$ (during the initial growth of $\mathrm{SiO}_{2}$ on $\mathrm{Si}$ ) may be used for accurate film-thickness measurement, a topic that will be discussed further in Sec. VI. The maximum minimum $p$ reflectance occurs exactly whenever $\phi_{p \mathrm{~B}}^{p}=$ $\phi_{\mathrm{B} 01}=\tan ^{-1} 1.46=55.59^{\circ}$, where $\phi_{\mathrm{B} 01}$ is the Brewster angle of the ambient-film (air-SiO${ }_{2}$ ) interface and is equal to the reflectance of the Si substrate at that angle (0.381). This is true over the entire range of $d$. Within the first period, the maximum of $\left|R_{p \text { min }}\right|$ occurs at a point marked $B^{\prime}$ in Fig. 2(a) that is nearly vertically above $B$. Between $B$ and $C$ (from $d_{B} \simeq 78 \mathrm{~nm}$ to $d_{C} \simeq$ $108 \mathrm{~nm}) \phi_{p B}^{p}=0$, i.e., $\left|R_{p \min }\right|$ occurs at normal incidence, and its value decreases as $d$ increases, as seen from the curve segment $B C$ of Fig. 2(b). For $d_{B}<d<$ $d_{C},\left|R_{p}\right|$ increases monotonically with $\phi$. [In the higher thickness intervals $I J$ and $P Q$ of Fig. 2(a), $\phi_{p \mathrm{~B}}^{p}=0$ also, but the associated $\left|R_{p}\right|$ vs $\phi$ curve is not monotonic.] At a point $C_{1}^{\prime}$ within the first film-thickness period we have $\left|R_{p \min }\right|=0 . \quad d_{C_{1}^{\prime}}=289.1 \mathrm{~nm}$ and $\phi_{p \mathrm{~B}}^{p}\left(d_{C_{1}^{\prime}}\right) \simeq \phi_{p \mathrm{~B}}^{p}$ $(0)=75.44^{\circ}$ are the polarizing ( $p$-suppressing) film 


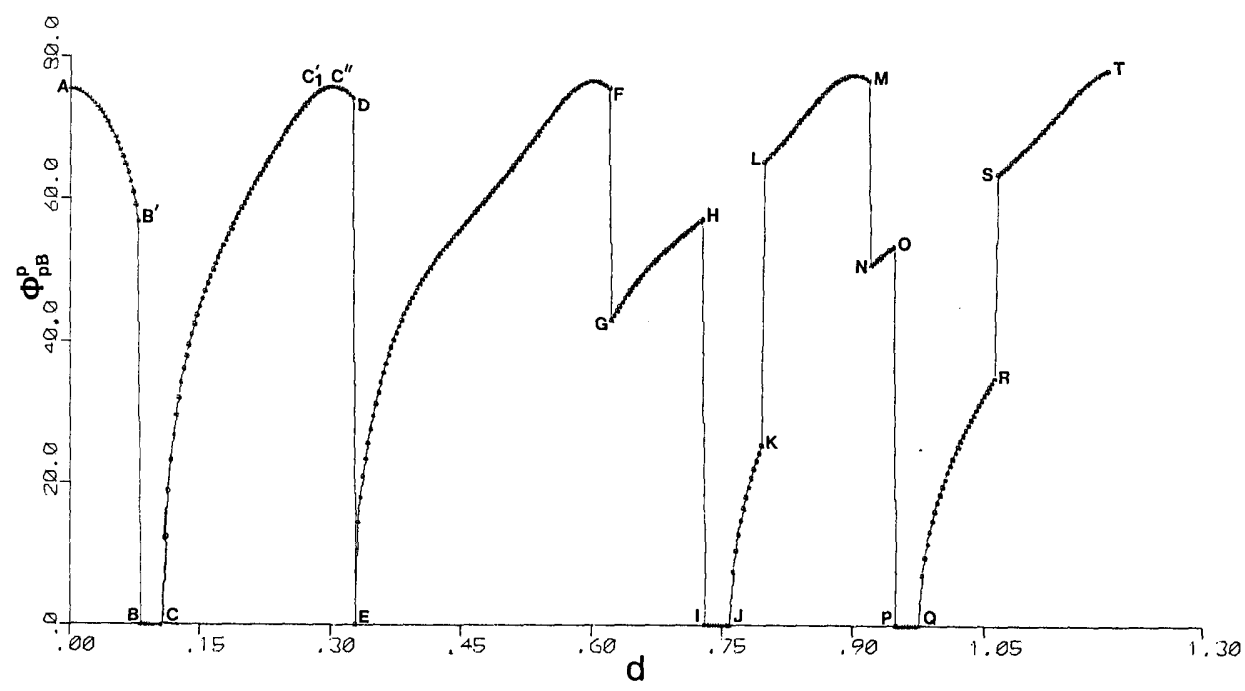

(a)

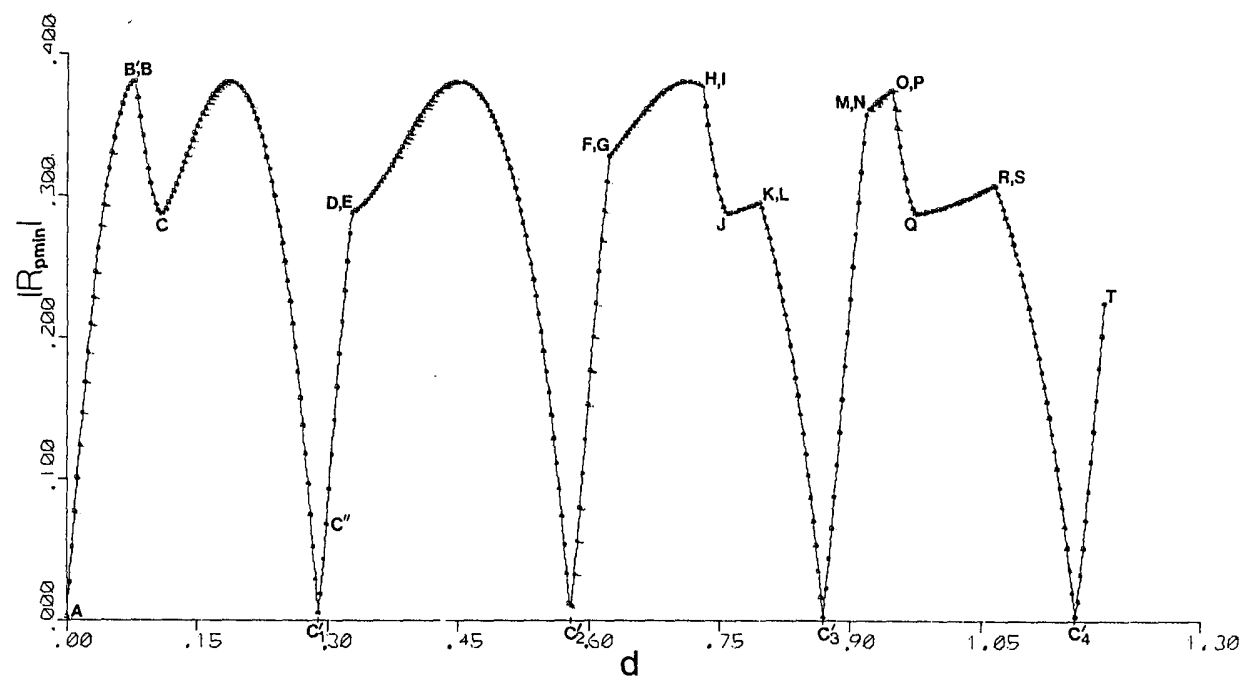

(b)

Fig. 2. (a) Pseudo-Brewster angle of absolute minimum $p$ reflectance $\phi_{p \mathrm{~B}}^{p}$ in degrees vs film thickness $d$ in microns for the air- $\mathrm{SiO}_{2}-\mathrm{Si}$ system at $\lambda=632.8 \mathrm{~nm}$. (b) Associated minimum $p$ reflectance $\left|R_{p \min }\right|$ vs $d$ in microns. (c) Plot of $\left|R_{p \text { min }}\right|$ vs $\phi_{p \mathrm{~B}}^{p}$ in degrees obtained by eliminating $d$ between Figs. 2(a) and (b).

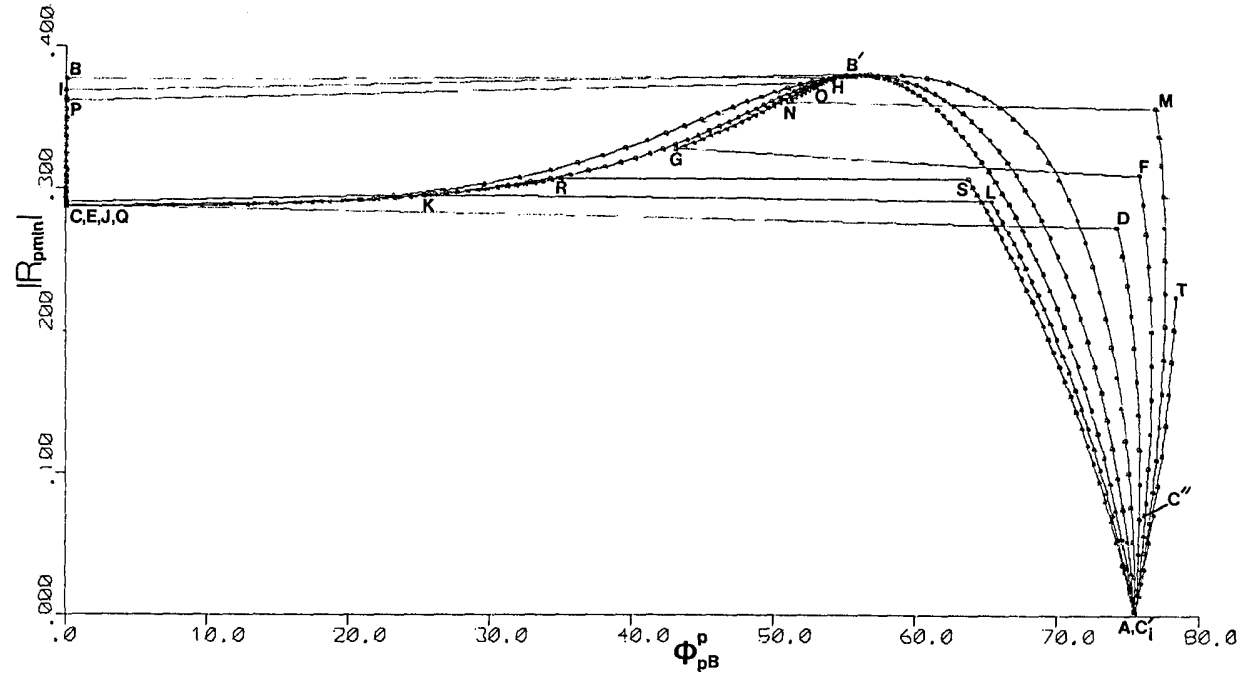

(c) 


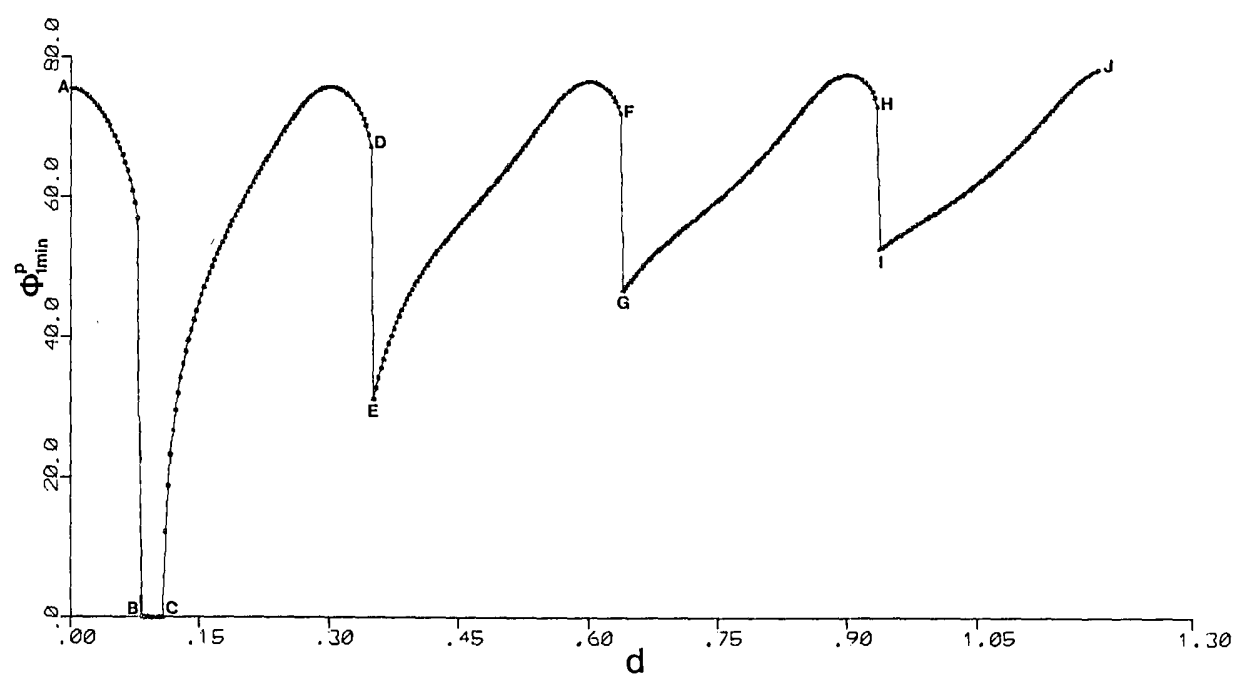

(a)

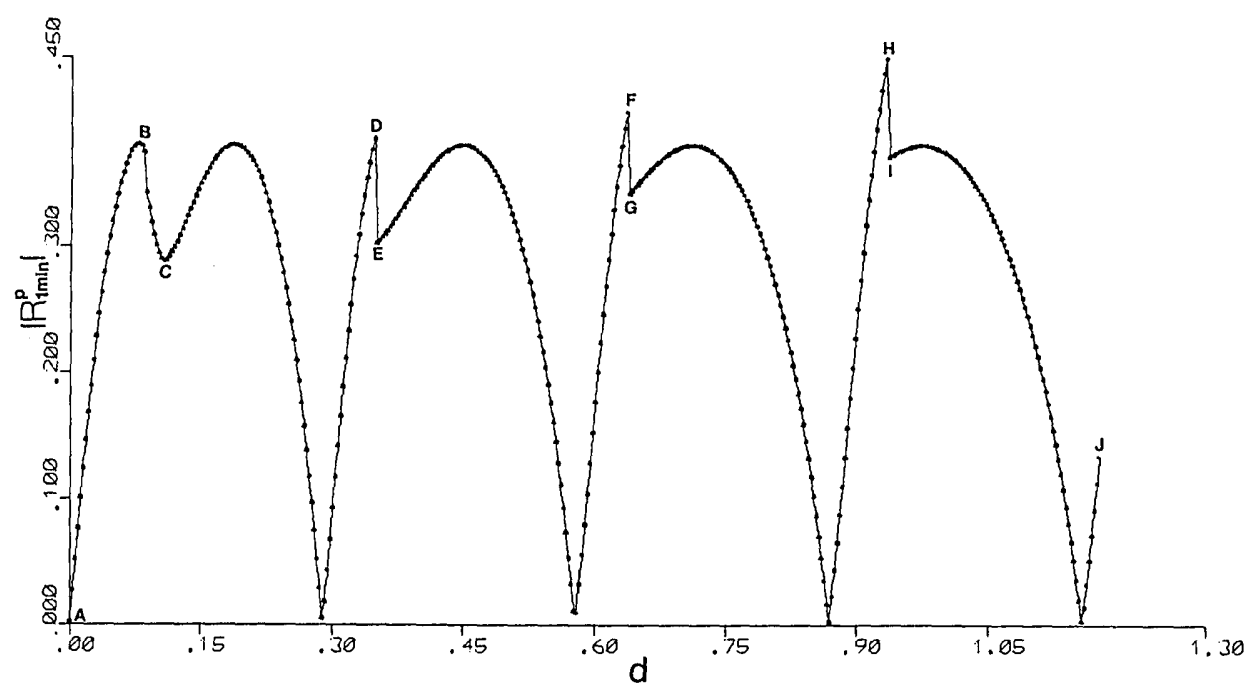

(b)

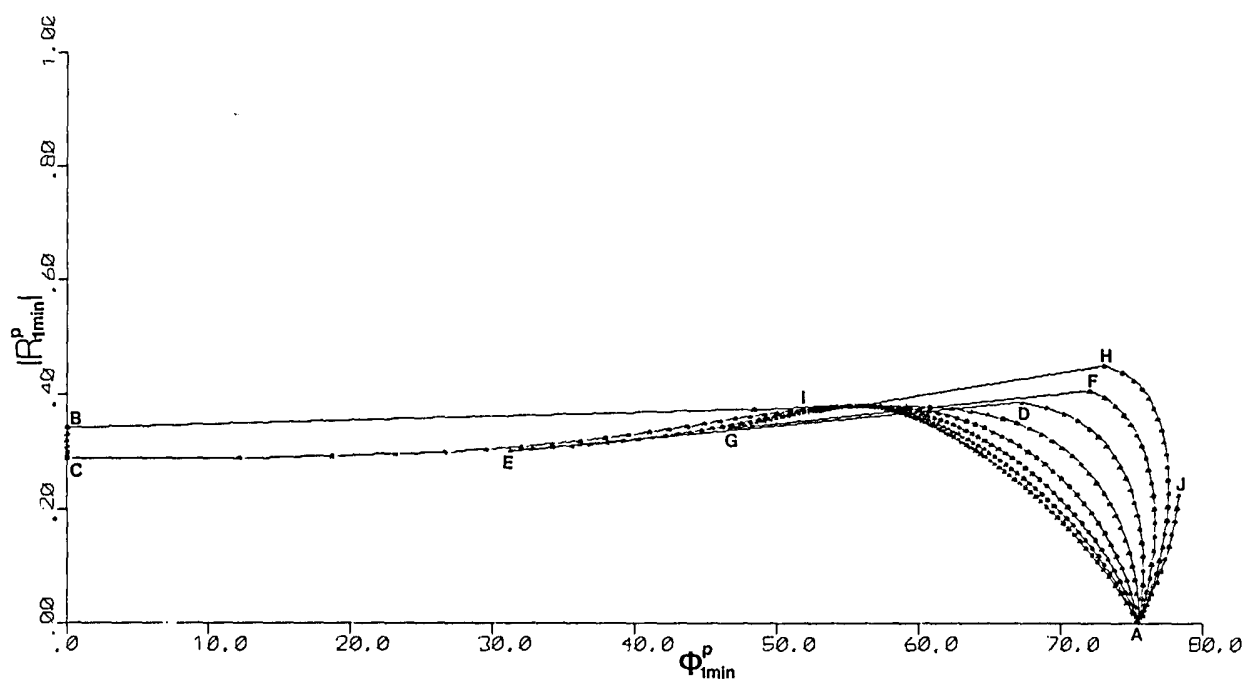

(c)

Fig. 3. (a) Angular position $\phi_{\text {? min }}^{p}$ in degrees of the first minimum of $\left|R_{p}\right|$ found under $90^{\circ}$ vs film thickness $d$ in microns for the air-SiO ${ }_{2}-\mathrm{Si}$ system at $\lambda=632.8$ nm. (b) Associated minimum $p$ reflectance $\left|R_{1 \min }^{p}\right|$ vs $d$ in microns. (c) Plot of $\left|R_{1 \min }^{p}\right|$ vs $\phi_{1 \text { min }}^{p}$ in degrees obtained by eliminating $d$ between Figs. 3(a) and (b). 
thickness and angle of incidence, respectively. Addition of integral multiples of $D_{75.44}=289.5 \mathrm{~nm}$ to $d_{C_{1}^{\prime}}$ leads to periodic repetition of this null condition as represented by points $C_{2}^{\prime}, C_{3}^{\prime}, C_{4}^{\prime} \ldots$ on the thickness axis in Fig. 2(b).

Experimental determination of $\phi_{p \mathrm{~B}}^{p}$ of a film-substrate system may require a complete $\left(0-90^{\circ}\right) \phi$ scan. An angle that is easier to determine is that of the first minimum of $\left|R_{p}\right|$ found under $90^{\circ}$. We denote this angle by $\phi_{1}^{p} \min$ and its associated minimum reflectance by $\left|R_{1 \text { min }}^{p}\right|$. Figures 3(a) and (b) show $\phi_{1 \text { min }}^{P}$ and $\left|R_{1 \text { min }}^{p}\right|$ as functions of $d$, and Fig. 3(c) shows $\left|R_{1 \text { min }}^{P}\right|$ vs $\phi_{1}^{P}$ min after elimination of $d$ as a common parameter. If Figs. 3(a) and 2(a) are overlapped, it will be noted that the first minimum of $\left|R_{p}\right|$ under $90^{\circ}$ is also the absolute minimum over the first thickness period and over limited segments of the higher periods.

Before concluding this section, we present for further illustration the location $\phi_{1 \text { max }}^{p}$ and magnitude $\left|R_{1 \text { max }}^{p}\right|$ of the first maximum of $\left|R_{p}\right|$ found under $90^{\circ}$. These are given as functions of $d$ in Figs. 4(a) and (b), respec- tively. In the thickness gap $B C$ (the same thickness range indicated by the same letters in Figs. 2 and 3) $\left|R_{p}\right|$ monotonically increases with $\phi$ and hence has no maximum. (A plot of $\left|R_{1 \text { max }}^{p}\right|$ vs $\phi_{1}^{p}{ }_{\text {max }}$ was found too complicated to be useful.) Higher-order critical points of the $\left|R_{p}\right|$ vs $\phi$ curve (and similarly for $\left|R_{s}\right|$ and $|\rho|$ ) were all determined for every $d$ but are excluded from further discussion to save space.

\section{Pseudo-Brewster Angle and Associated Minimum Reflectance for the $s$ Polarization}

Whereas the Brewster and pseudo-Brewster angles are usually defined for $p$-polarized light reflection from single interfaces, similar definitions become equally applicable to the $s$ polarization when one considers a system with two (or more) interfaces.

The pseudo-Brewster angle for the $s$ polarization $\phi_{p \mathrm{~B}}^{s}$ is defined as that angle at which $\left|R_{s}\right|$ reaches its absolute (lowest) minimum value $\left|R_{s \text { min }}\right| . \phi_{p \mathrm{~B}}^{s}$ and $\left|R_{s \text { min }}\right|$ are plotted individually vs $d$ in Figs. 5(a) and (b), respectively, and against each other in Fig. 5(c). $\phi_{p \mathrm{~B}}^{s}(d)$

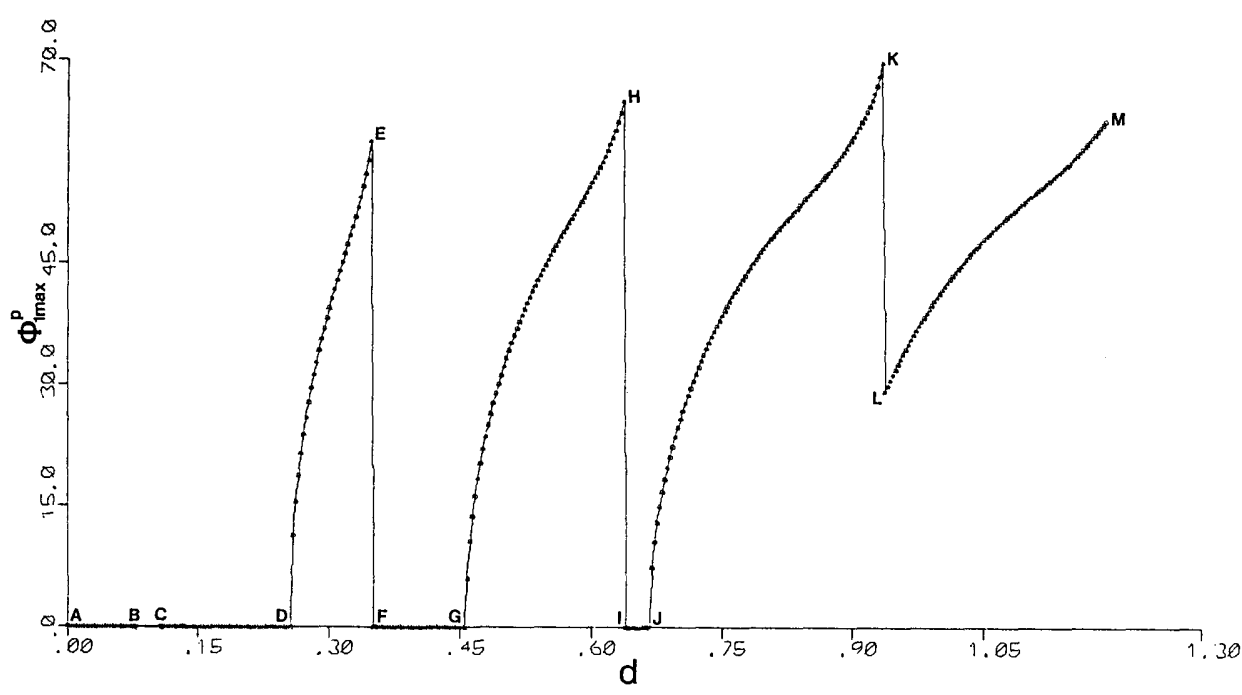

(a)

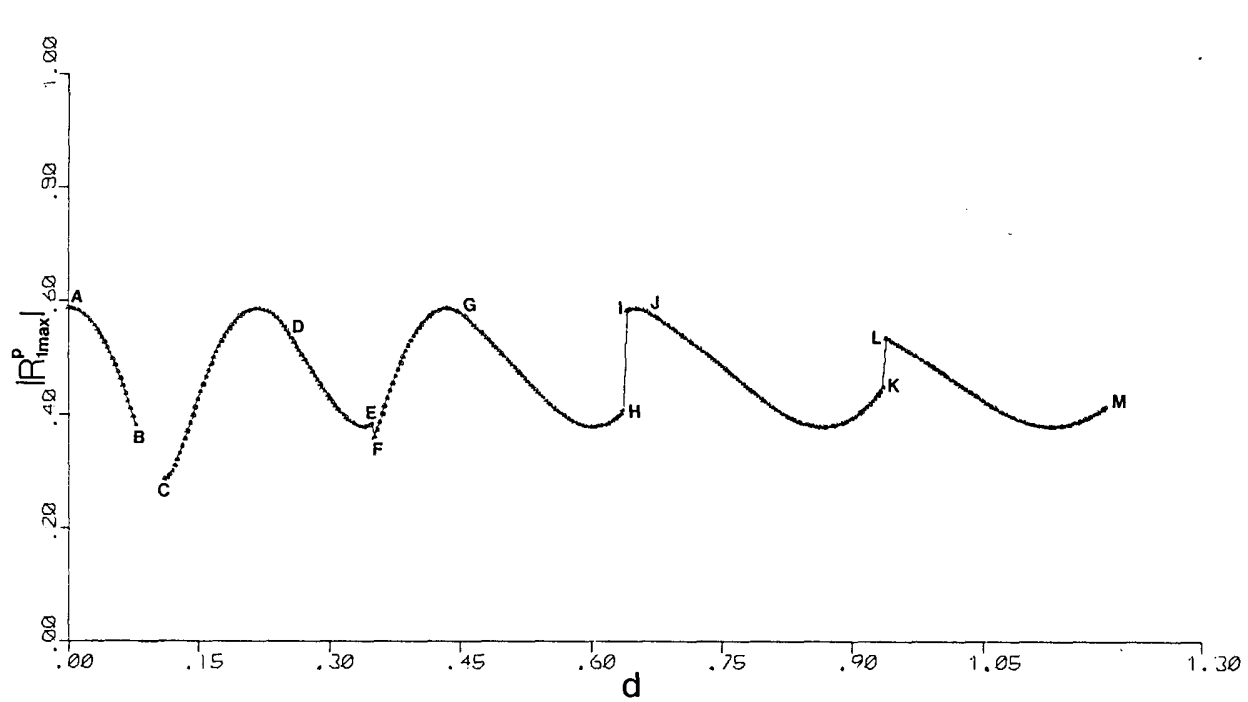

(b)
Fig. 4. (a) Same as in Fig. 3(a) but for the first maximum found under $90^{\circ}$. (b) Associated maximum $p$ reflectance $\left|R_{1 \text { max }}^{p}\right|$ vs $d$ in microns. 


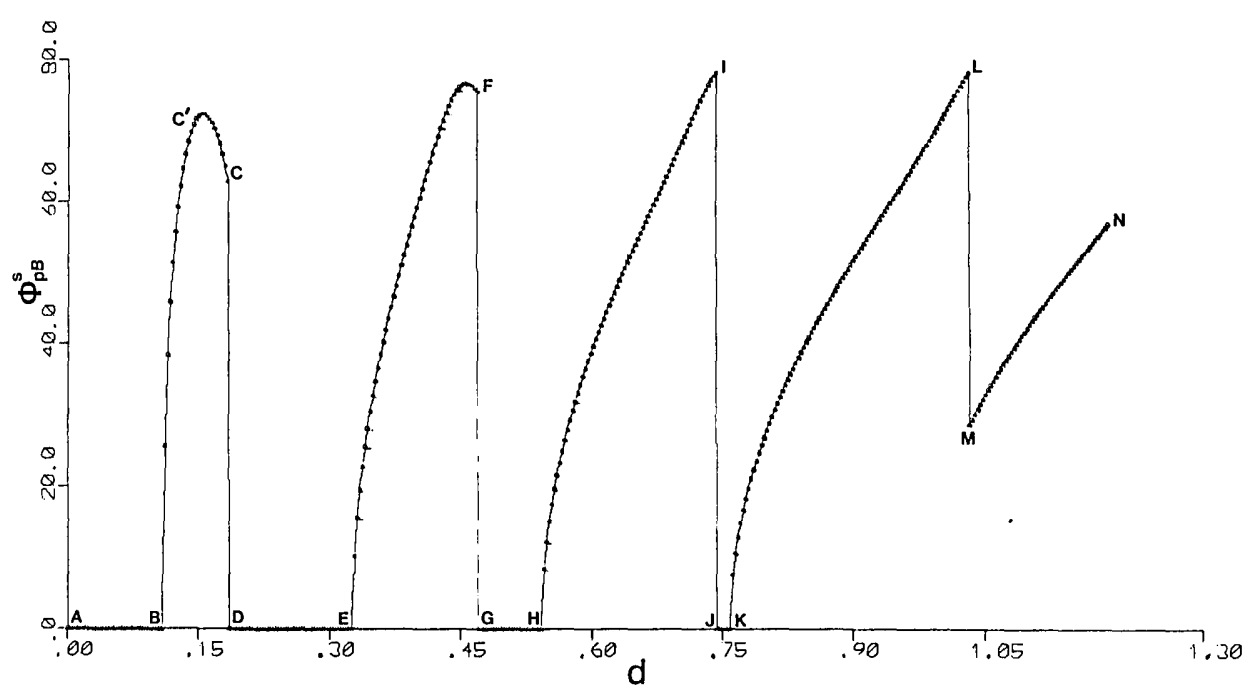

(a)

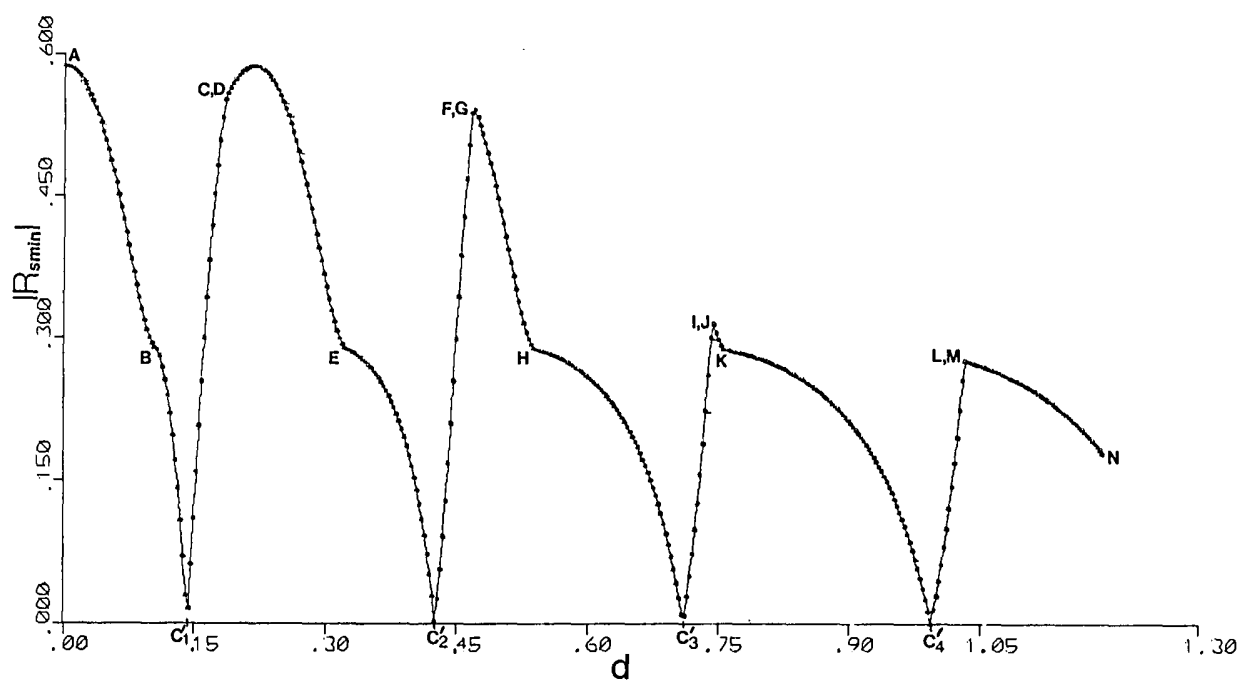

(b)

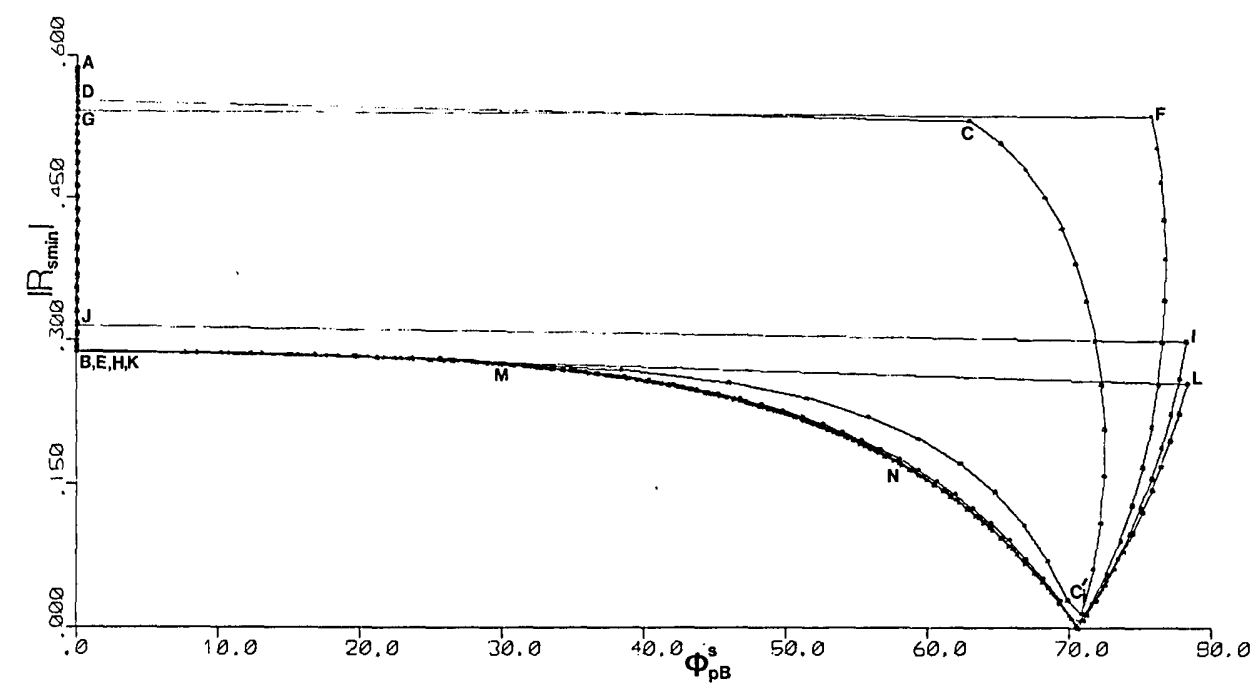

(c)
Fig. 5. (a) Pseudo-Brewster angle of absolute minimum $s$ reflectance $\phi_{p \mathrm{~B}}^{s}$ in degrees vs film thickness $d$ in microns for the air- $\mathrm{SiO}_{2}-\mathrm{Si}$ system at $\lambda=632.8 \mathrm{~nm}$. (b) Associated minimum $s$ reflectance $\left|R_{s \min }\right|$ vs $d$ in microns. (c) Plot of $\left|R_{s \text { min }}\right|$ vs $\phi_{p \mathrm{~B}}^{s}$ in degrees obtained by eliminating $d$ between Figs. 5(a) and (b). 


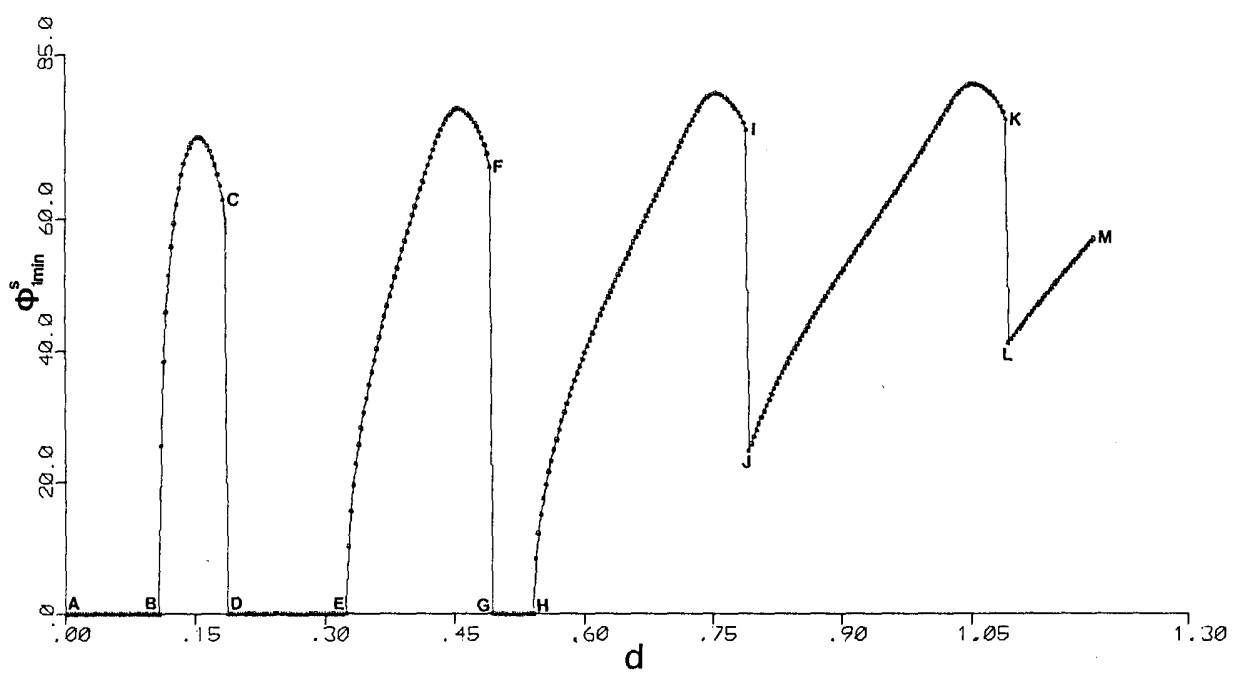

(a)

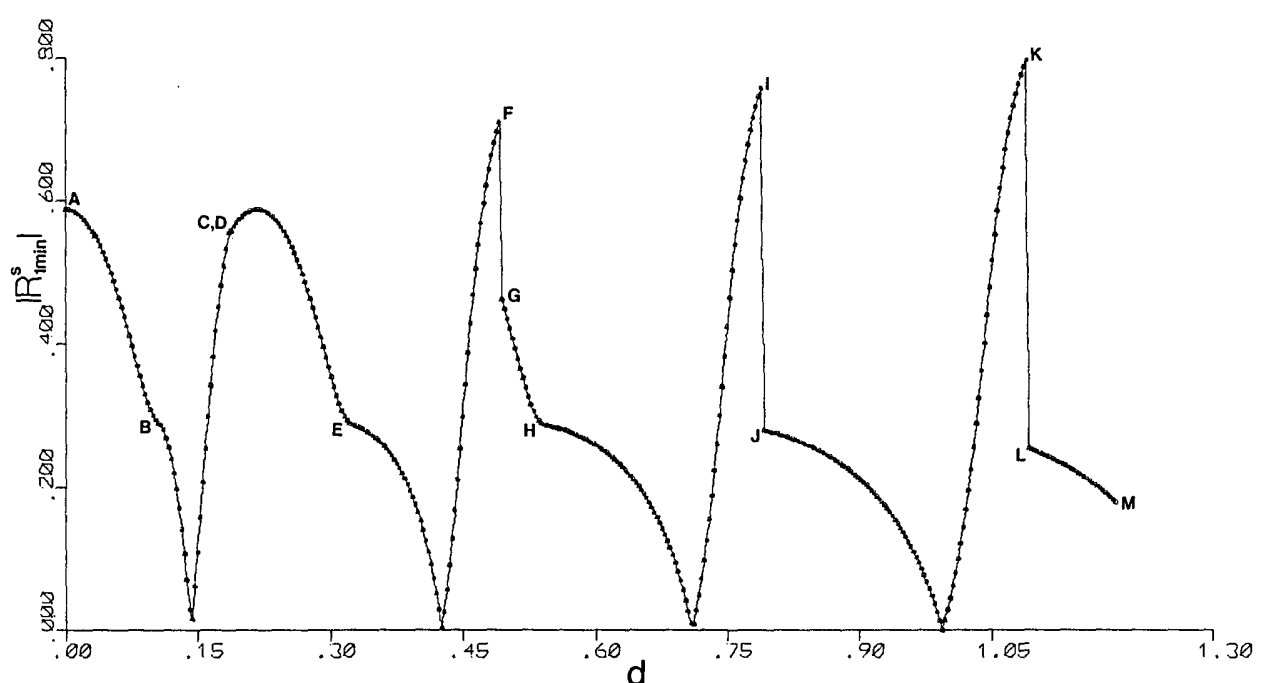

(b)

Fig. 6. (a) Angular position $\phi_{1 \text { min }}^{s}$ in degrees of the first minimum of $\left|R_{s}\right|$ found under $90^{\circ}$ vs film thickness $d$ in microns for the air- $\mathrm{SiO}_{2}-\mathrm{Si}$ system at $\lambda=632.8$ nm. (b) Associated minimum $s$ reflectance $\left|R_{1 \text { min }}^{s}\right|$ vs $d$ in microns. (c) Plot of $\left|R_{1 \text { min }}^{s}\right|$ vs $\phi_{1 \text { min }}^{s}$ in degrees obtained by eliminating $d$ between Figs. 6(a) and (b).



(c) 
and $\left|R_{s \min }\right|(d)$ are aperiodic functions. Within the first film-thickness period $(0 \leq d \leq 0.3 \mu \mathrm{m})$, we have $\phi_{p \mathrm{~B}}^{s}$ $=0$ except between points $B\left(d_{\mathrm{B}} \simeq 108 \mathrm{~nm}\right)$ and $D\left(d_{\mathrm{D}}\right.$ $\simeq 184 \mathrm{~mm})$. At a point $C_{1}^{\prime}\left(d_{C_{1}^{\prime}}=141.8 \mathrm{~nm}\right.$ and $\phi_{p \mathrm{~B}}^{s}=$ $\left.70.56^{\circ}\right),\left|R_{s \min }\right|=0$. This represents the condition when the film-substrate system acts as an $s$-suppressing reflection polarizer. Addition of integral multiples of $D_{70.56}=283.9 \mathrm{~nm}$ to $d_{C_{1}^{\prime}}$ repeats this null condition periodically at higher thickness. This is represented by the points $C_{2}^{\prime}, C_{3}^{\prime} \ldots$, all of which correspond to the same angle $70.56^{\circ}$.

The angular position $\phi_{1 \min }^{s}$ and magnitude $\left|R_{1 \min }^{s}\right|$ of the first minimum of $\left|R_{s}\right|$ under $90^{\circ}$ are plotted in Figs. 6(a) and (b), respectively, vs $d$ and against each other in Fig. 6(c). Overlapping Figs. 6(a) and 5(a) shows that the first minimum under $90^{\circ}$ is also the absolute minimum of $\left|R_{s}\right|$ (i.e., $\phi_{p \mathrm{~B}}^{s}=\phi_{1 \mathrm{~min}}^{s}$ ) over the first filmthickness period and over segments of the remaining three periods.

\section{Second-Brewster Angle and Associated Minimum Ratio of $p$ and $s$ Reflectances}

The second-Brewster angle $\phi_{2 \mathrm{~B}}$ is defined as that angle of incidence at which the ratio of $p$ and $s$ reflectances $|\rho|=\left|R_{p} / R_{s}\right|$ reaches its absolute minimum value $\left|\rho_{\min }\right| . \quad \phi_{2 \mathrm{~B}}$ and $\left|\rho_{\min }\right|$ are plotted individually vs $d$ in Figs. 7(a) and (b), respectively, and against each other in Fig. $7(\mathrm{c})$. Again the functions $\phi_{2 \mathrm{~B}}(d)$ and $\left|\rho_{\min }\right|(d)$ are not periodic. A periodic feature, however, is the null condition $\left|\rho_{\min }\right|=0$, which occurs at the equispaced thicknesses that make $\left|R_{p}\right|=0$.

Let the first extremum of $|\rho|$ found under $90^{\circ}$ be located at $\phi_{1 \text { ext }}$ and let its magnitude be $\left|\rho_{1 \text { ext }}\right|$. If $\left|\rho_{1 \text { ext }}\right|<1$, the extremum is a minimum, and if $\mid \rho_{1}$ ext $\mid$ $>1$, it is a maximum. $\phi_{1 \text { ext }}(d)$ and $\left|\rho_{1 \text { ext }}\right|(d)$ are plotted in Figs. 8(a) and (b). The spikes in Fig. 8(b) actually reach infinite height at thicknesses that make $|\rho|=\infty$. This happens when $\left|R_{s}\right|=0$, i.e., at the equispaced $s$-polarizing film thicknesses given in Sec. IV. Figure $8(\mathrm{c})$ gives a magnified view of the first spike that appears in Fig. 8(b). Intersections of the curve of Fig. 8(c) with the line $|\rho|=1$ separate the regions where the first extremum is maximum and minimum. When $\left|\rho_{1 \text { ext }}\right|$ was plotted vs $\phi_{1 \text { ext }}$, the resulting graph looked too complicated to be useful.

\section{Applications}

Besides extending the concepts of Brewster, pseudo-Brewster, and second-Brewster angles for single interfaces to systems with two interfaces for both the $p$ and $s$ polarizations, the present study is also useful in suggesting new techniques for film-thickness measurement and control. (The results given here are for the technologically important $\mathrm{SiO}_{2}-\mathrm{Si}$ system at the common $\mathrm{He}-\mathrm{Ne}$ laser wavelength of $632.8 \mathrm{~nm}$.) An example has already been noted in Sec. III; others will now be given.

Suppose it is required to grow a $\mathrm{SiO}_{2}$ layer on $\mathrm{Si}$ of a thickness of $\sim 100 \mathrm{~nm}$ subject to a tolerance of about $\pm 10 \mathrm{~nm}$. This happens to be roughly the thickness band denoted by $B C$ in Fig. 2(a). A simple test that indicates that the layer thickness is within this range is to verify that the reflectance of the oxidized Si wafer for $p$-polarized 632.8-nm light monotonically increases with $\phi$ from normal to grazing incidence. Such a novel test is expected to continue to be useful at other wavelengths for other film-thickness bands. Other criteria that can be used for film-thickness control within certain ranges are that (1) $\left|R_{s}\right|$ has a minimum at oblique incidence [band $B D$, Fig. 5(a)] and (2) $|\rho|>1$ [e.g., band $B D$, Fig. $8(c)]$.

Another important contribution to film-thickness measurement is the ability to determine uniquely the thickness without knowledge of the period (order) number. (This presents a problem, e.g., in ellipsometry. ${ }^{6}$ ) Figure 7(c) indicates that measurements of $\phi_{2 B}$ and $\left|\rho_{\min }\right|$ uniquely determine $d$. Difficulty in applying this technique occurs only when $d$ is at or near one of the p-suppressing film thicknesses, i.e., near point $A$ in Fig. $7(\mathrm{c})$. Figures 2(c), 3(c), 5(c), and 6(c) suggest that other similar methods for unique film-thickness determination can be used with varying degrees of accuracy.

In the course of this work, we have plotted many reflectance vs $\phi$ curves (one of which is Fig. 1). We have found that for certain film thicknesses, it is possible to achieve a reflectance that varies very little with $\phi$ up to a large angle. We present two examples. Figure 9 shows $\left|R_{p}\right|$ vs $\phi$ for $d=0.27 D_{90}=80.3 \mathrm{~nm}$. [This corresponds to transition point $B$ in Fig. 2(a).] The reflectance deviates by $<4.7 \%$ from its normal-incidence value over the range $0<\phi<60^{\circ}$. Figure 10 shows $\left|R_{s}\right|$ vs $\phi$ for $d=0.61 D_{90}=181.4 \mathrm{~nm}$. [This corresponds to point $C$ next to transition point $D$ in Fig. 5(a).] In this case, $\left|R_{s}\right|$ is within $2.3 \%$ of its value at normal incidence for $0<\phi<70^{\circ}$. This may be useful in wide-angle beam deflection applications.

\section{Summary}

Critical points of the $p$ and $s$ reflectances and their ratio, when plotted vs the angle of incidence $\phi$ at a given thickness $d$ of a transparent film on an absorbing substrate, are determined by numerical solution of Eq. (2). The results are plotted vs $d$ over a thickness range of up to four thickness periods for the air- $\mathrm{SiO}_{2}-\mathrm{Si}$ system at $\lambda=632.8 \mathrm{~nm}$. Interesting aperiodic functions are obtained (Figs. 2-8). The procedure can, of course, be applied to other film-substrate systems, at other wavelengths, or for other thickness ranges.

The behavior of the critical points as functions of $d$ can be utilized as the basis of new techniques for filmthickness measurement and control. For example, a simple test can be applied to verify that the thickness of $\mathrm{SiO}_{2}$ on $\mathrm{Si}$ is within $\pm \sim 10 \mathrm{~nm}$ of $\sim 100-\mathrm{nm}$ nominal thickness by checking only that the reflectance of the oxidized Si wafer for the incident $p$-polarized $\mathrm{He}-\mathrm{Ne}$ laser light (of $632.8-\mathrm{nm}$ wavelength) increases monotonically with $\phi$ as the sample is rotated from normal to grazing incidence. Another important advantage of using critical-point data [e.g., the second Brewster angle and its associated absolute minimum reflectance ratio, Fig. 7 (c)] is the ability to determine film thickness uniquely without prior knowledge of the thickness period or order number. 


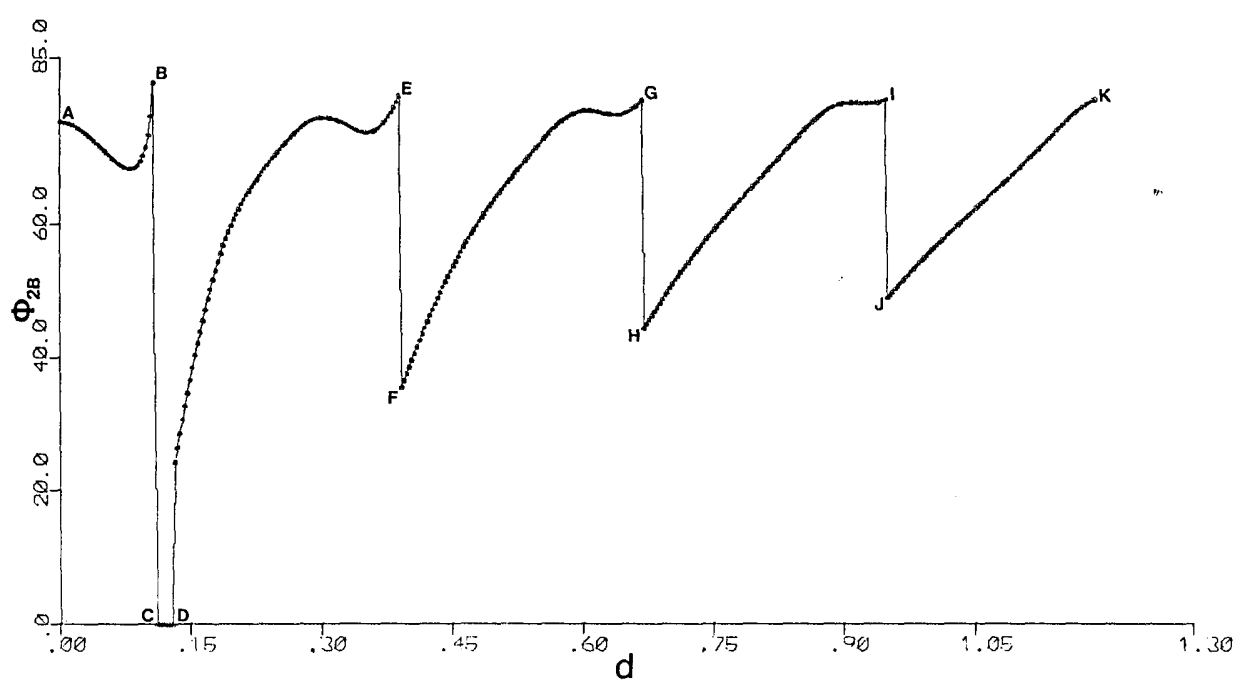

(a)

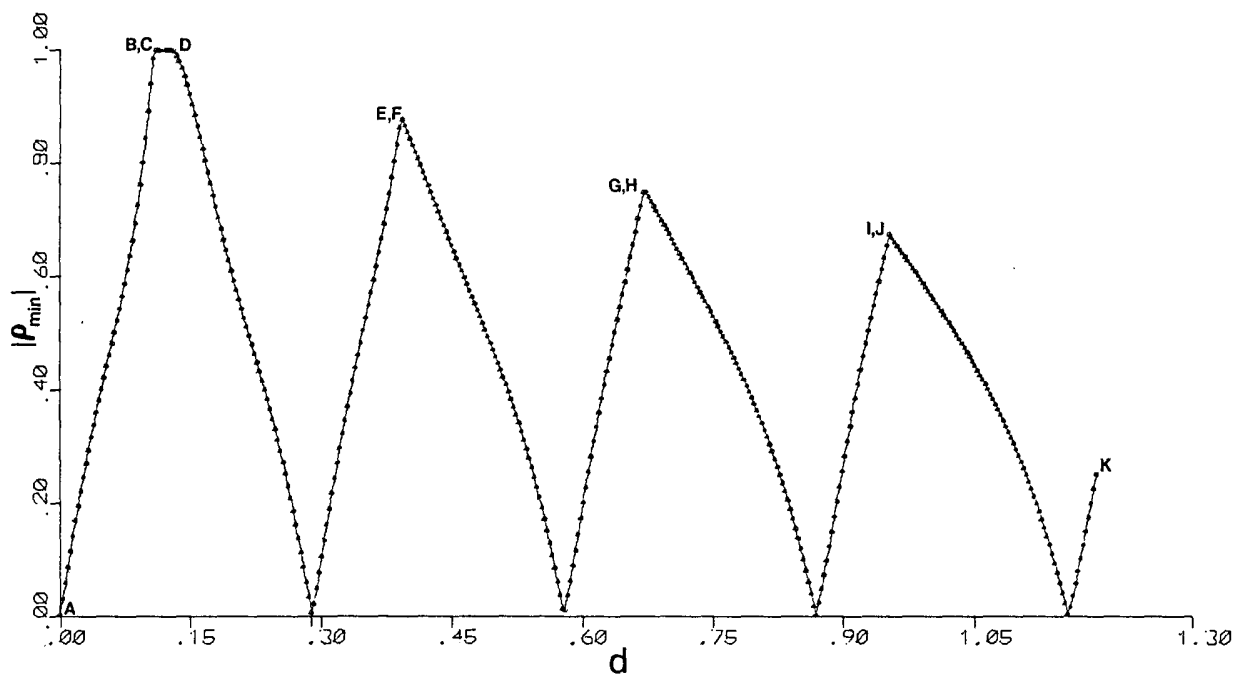

(b)

Fig. 7. (a) Second-Brewster angle $\phi_{2 \mathrm{~B}}$ in degrees of absolute minimum reflectance ratio $\left|\rho_{\min }\right|$ vs film thickness $d$ in microns for the air- $\mathrm{SiO}_{2}-\mathrm{Si}$ system at $\lambda=632.8$ nm. (b) $\left|\rho_{\min }\right|$ vs $d$ in microns. (c) $\left|\rho_{\min }\right|$ vs $\phi_{2 \mathrm{~B}}$ in degrees obtained by eliminating $d$ between Figs. 7(a) and (b).

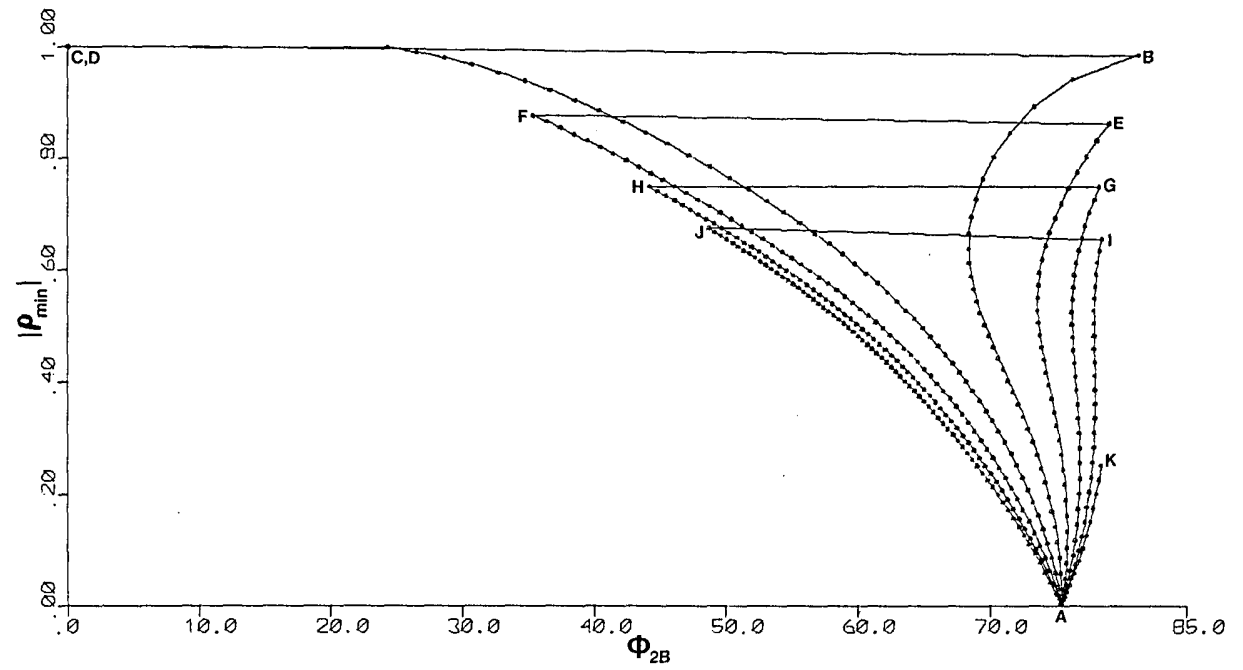

(c) 


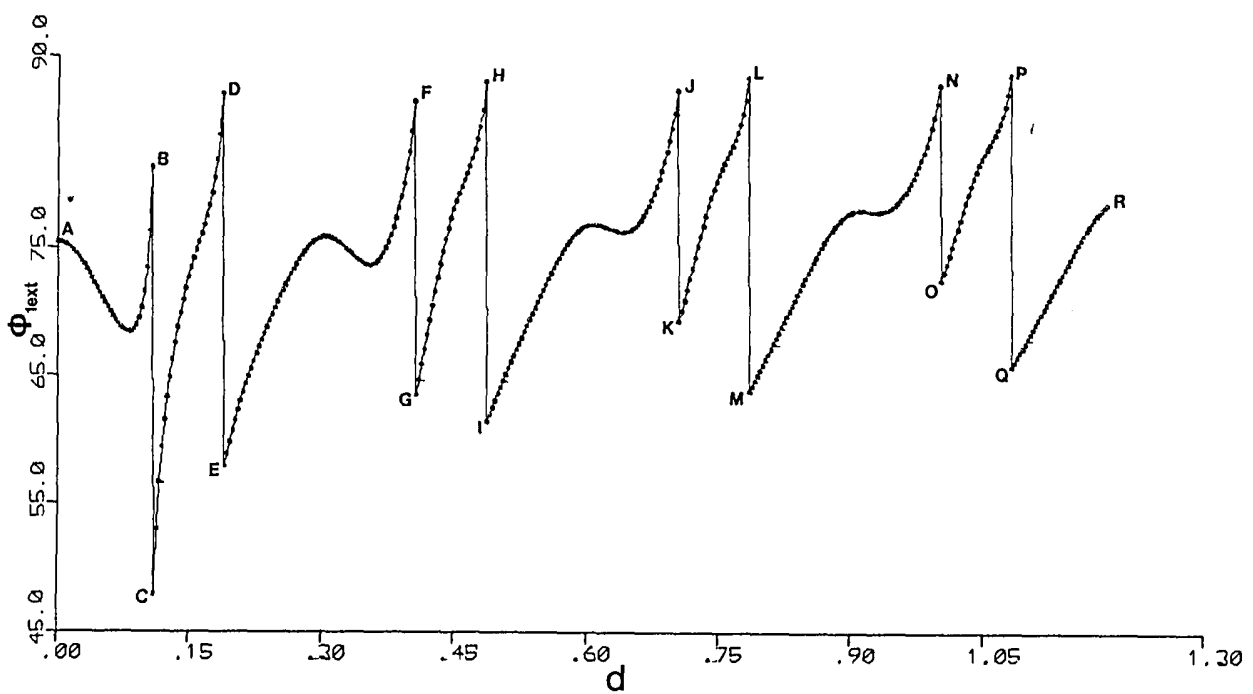

(a)

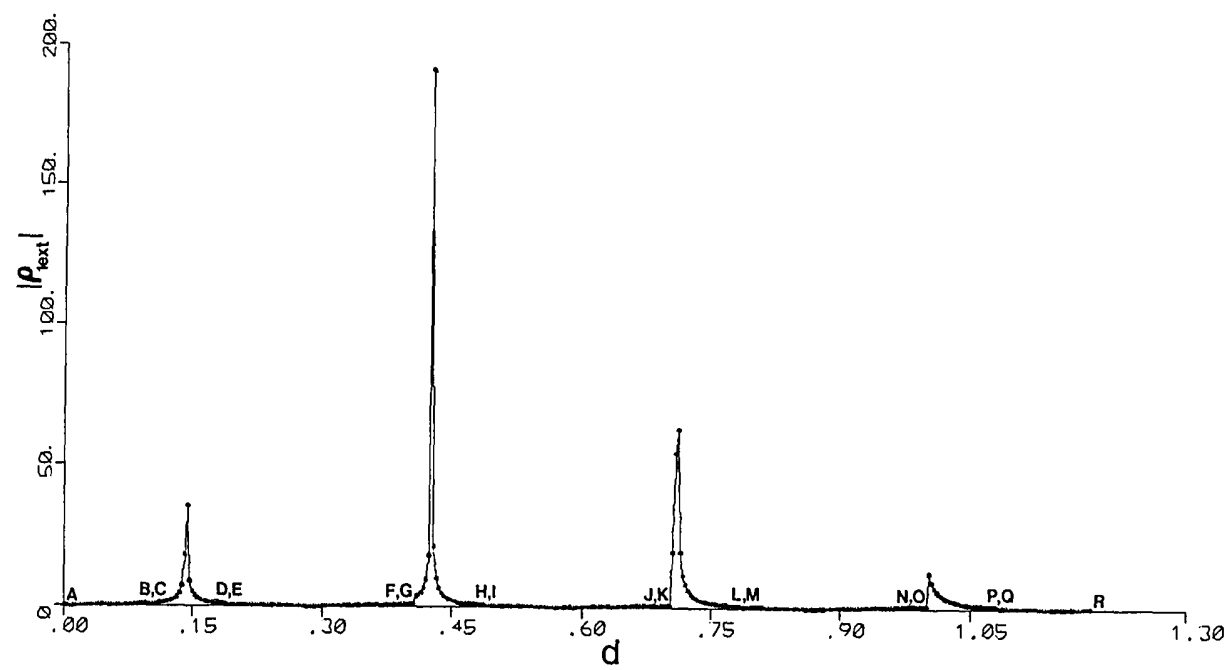

(b)

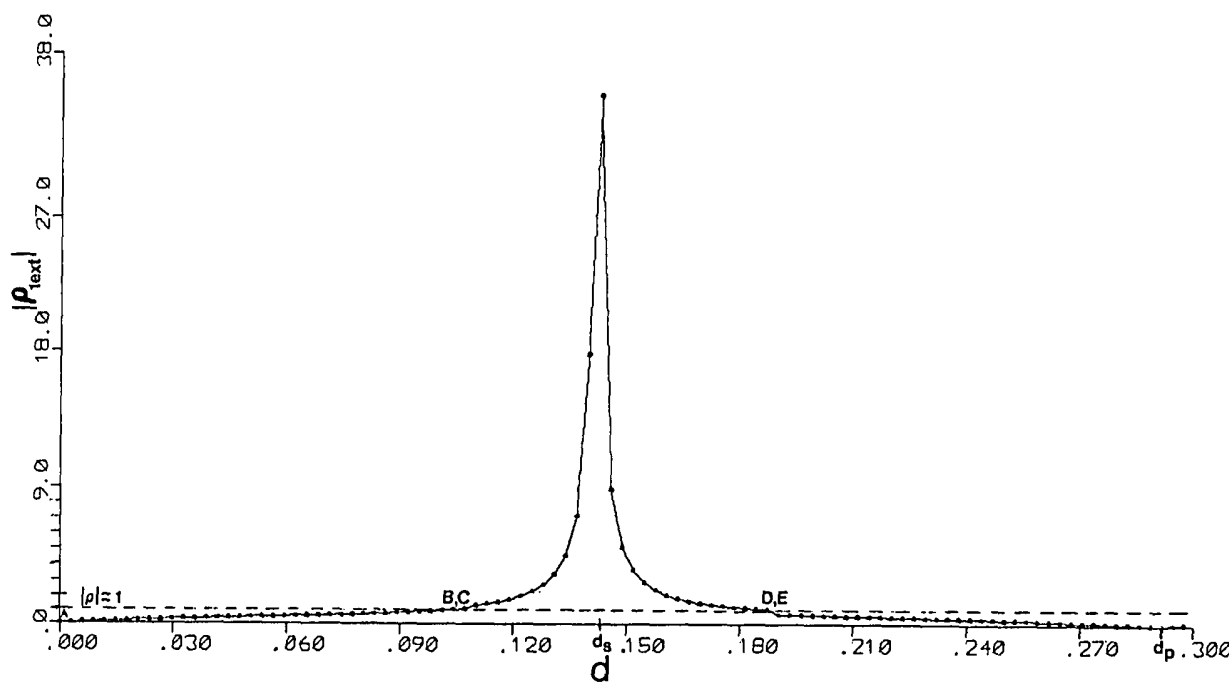

(c)

Fig. 8. (a) Angular position $\phi_{1}$ ext in degrees of the first extremum (maximum or minimum) of the reflectance ratio $|\rho|$ found under $90^{\circ}$ vs film thickness in microns for the air- $\mathrm{SiO}_{2}-\mathrm{Si}$ system at $\lambda=$ $632.8 \mathrm{~nm}$. (b) Associated $\left|\rho_{1 \text { ext }}\right|$ vs $d$ in $\mu \mathrm{m}$. (c) Expansion of Fig. 8 (b) over the first thickness period only. $d_{p}$ and $d_{s}$ are the $p$ and $s$ polarizing film thicknesses. 


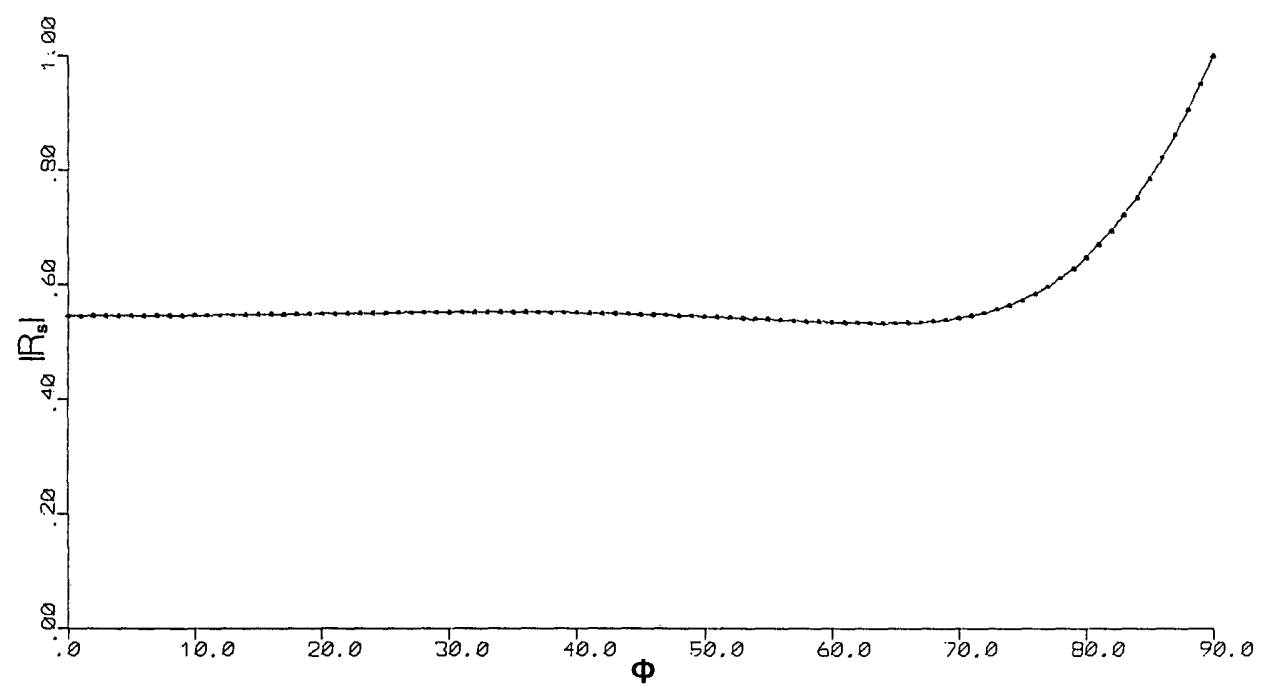

Fig. 9. Same as in Fig. 1 but for $d=0.27 D_{90}=80.3 \mathrm{~nm}$.

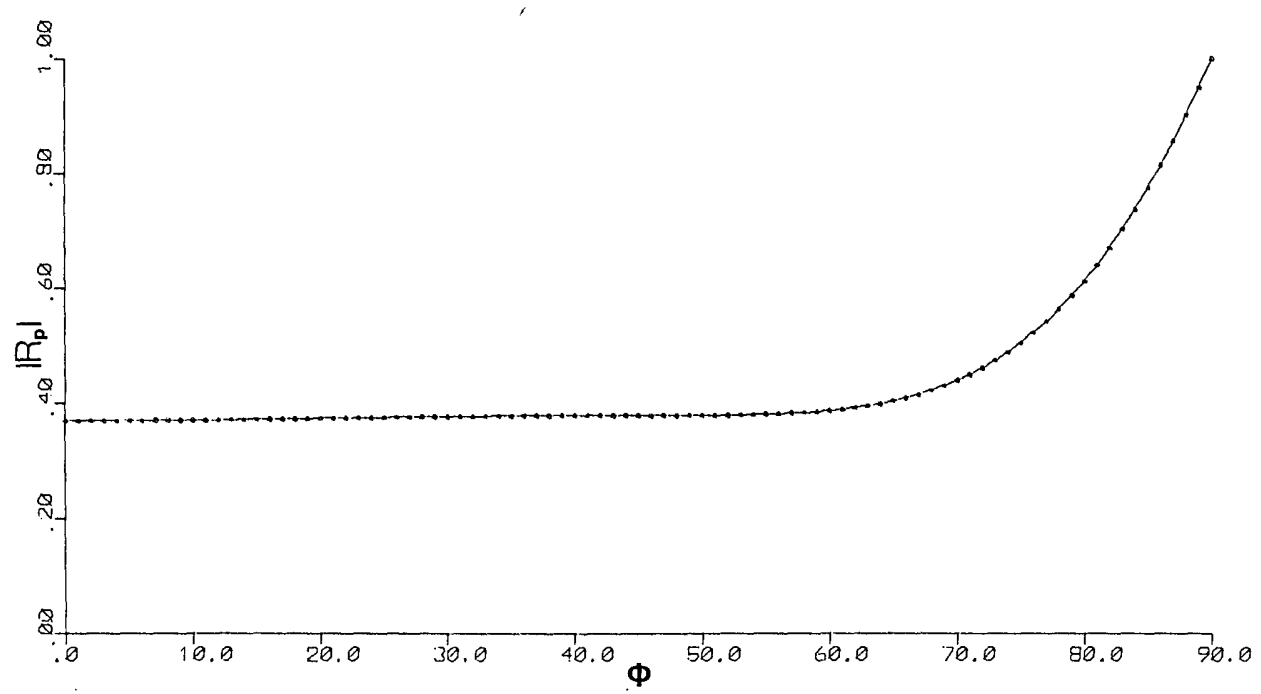

Fig. 10. Same as in Fig. 1 but for the $s$ polarization and $d=0.61 D_{90}=181.4 \mathrm{~nm}$.

Finally, we have noted that for certain film thicknesses it is possible to achieve reflectance that varies very little with angle of incidence up to $60-70^{\circ}$, as shown by Figs. 9 and 10, for example.

This work was supported by the National Science Foundation grant DMR-8018417.

This paper was presented at the Annual Meeting of the Optical Society of America, New Orleans, 17-20 Oct. 1983.

\section{References}

1. R. M. A. Azzam and M. E. R. Khan, Appl. Opt. 22, 253 (1983).

2. W. A. Pliskin, in Progress in Analytic Chemistry, Vol. 2, E. M. Murt and W. G. Guldner, Eds. (Plenum, New York, 1969), pp. 1-34.

3. A direct search method is used. An initial iteration step $\Delta \phi_{\text {in }}\left(1^{\circ}\right)$ is selected, and $\phi$ is scanned in one direction (from $90^{\circ}$ to 0 ). A root of Eq. (2) exists between two successive $\phi$ values whenever its left-hand side changes sign. The root is refined by successive reduction of $\Delta \phi(0.1,0.01, \ldots)$ until the absolute value of the lefthand side of Eq. (2) falls below $10^{-6}$. The value of the function $|Z|$ is evaluated at the root, and the search is resumed for another root.

4. R. M. A. Azzam, J. Opt. Soc. Am. 72, 1187 (1982).

5. R. M. A. Azzam, Opt. Acta 30, 1113 (1983).

6. See, for example, R. M. A. Azzam and N. M. Bashara, Ellipsometry and Polarized Light (North-Holland, Amsterdam, 1977), pp. 316-317. 
Books continued from page 4117

they form a continuous structure, as in microchannel plate multipliers. A short section on photon counting is included because many applications of photomultipliers involve photon counting. Gas-filled phototubes are similar to vacuum phototubes in having two electrodes but differ in that they are filled with a gas, usually argon at a pressure of 0.1 torr. Photoelectrons from the cathode ionize the gas molecules to generate additional electrons, thus providing gain. These tubes are not the same as photoionization chambers wherein the photons ionize the gas.

Semiconductor detectors make use of the internal photoeffect that creates electric charge carriers. They may be divided into photoconductors, junction photodetectors, and avalanche photodiodes.

All of the types of detector mentioned above are discussed in terms of the four general detector properties listed in chapter 3 . In addition there are short sections on the applications of the detectors.

The ultimate chapter is entitled Detector Attachments. It includes filters for spectral matching, attenuators, modulators, diffusers for improving the spatial uniformity of response, and attachments for radiance or luminance measurements. There is a short section on the measurement of $\mathrm{cw}$ laser radiation.

The first appendix contains compiled data on detectors, and the second consists of numerical tables.

The book is an excellent and thorough discussion of radiation detectors for the $2000 \AA$ to $3 \mu \mathrm{m}$ spectral region. It is well written and contains sufficient information to acquaint the reader with the advantages and disadvantages, as well as modes of operation, of many different radiation detectors. Of special interest to all users of detectors is chapter 3 on the general properties of detectors. This reviewer's experience has been limited to photomultipliers and vacuum phototubes, used in the vacuum ultraviolet, and it was interesting to learn about the idiosyncracies of thermal and semiconductor detectors.

Those interested in pursuing the subject to even shorter wavelengths than $2000 \AA$ will find a companion article in Heroux's, "Absolute Photon Counting in the Ultraviolet," in the book SPECTROMETRIC TECHNIQUES, Vol. 2 (Ed. G. Vanasse), Academic Press, 1981.

\section{W. R. HUNTER}

The Solar Spectrum $3609 \AA-2095 \AA$ from the Echelle Spectrograph Flown in 1961 and 1964. By CHARLOTTE E. MOORE, RICHARD TOUSEY, and CHARLES M. BROWN. Naval Research Laboratory, Washington, D.C., 1982. 176 pp. $\$ 16.00$.

This table-NRL Report 8653-is an extension of Rowland's Preliminary Table of Solar Spectrum Wavelengths. It is the final listing of lines derived from NRL high-resolution echelle photographs from Aerobee rockets flown in 1961 and 1964 to get above the ozone layer. Solar wavelengths are given to $0.01 \AA$ and estimated solar intensities are listed on a visual scale of 1 to 9 . There are 6150 lines reported of which $80 \%$ are identified.

Copies may be requested from the Naval Research Laboratory, Code 4173B, Washington, D.C. 20375.

FRANKLIN S. HARRIS, JR.
The Photic Field. By P. MOON and D. SPENCER. MIT Press, Cambridge, 1981. 257 pp. $\$ 25.00$.

The authors have a long and rich history of publications in the field of illuminating engineering, with many of those publications considered seminal. This volume is not, unfortunately, in that tradition. It is apparent that an attempt has been made to unify photometrics, as applied to illuminating engineering, using field theory. The attempt is freighted with two difficulties: terms and notation. The authors choose to use names and notation for standard photometric concepts that are part of a naming system they developed after the Second World War. The international lighting engineering community long ago established an agreed-on photometric vocabulary, which does not include any the authors' suggested terms. There is little excuse then, to read about Helios, $\mathrm{H}$, in this book when the common well-known quantity luminance, $L$, is being discussed. A more serious issue is that of whether field theory is unifying, or even useful, for photometrics and illuminating engineering. Reasonable criteria to use are practical utility, generality, and the ease with which new insights can be gained. Although the authors state that their intention is to bring formal elegance and completeness to photometry and its application to illuminating engineering using field theory, it is this reviewer's opinion that this is not accomplished in the present volume.

There are many well-known results presented in the authors' curious terminology, cast into the field theory formalism:

(1) The calculation of numerical values for radiant exchange form factors or configuration factors is made simpler by invoking Gauss's Theorem of Stokes Theorem, but one need not invoke field theory. In the present case, it obscures physical interpretation and insight into radiative transfer problems.

(2) Reflectance is presented as a two-component quantity, with specular and diffuse components. Nicodemus and others have shown that this is an unnecessary artificial complexity. The bi-directional reflectance distribution function (BRDF) describes the directional reflectance of real surfaces in a manner suitable for all illuminating engineering and photometric purposes.

(3) A large portion of the book deals with what would commonly be called the calculation of the direct component of illuminance at a point. Again, the formalisms of field theory obscure what is happening in otherwise simple physical systems.

An entire chapter of this book is devoted to showing that vector potentials are not useful in such lighting calculations.

Ultimately, the interesting and difficult practical questions are ignored: How does one calculate the illuminance produced by real sources of light, ones which are not (by design) Lambertian emitters? How are interreflections accounted for in enclosures other than spheres and cylinders? There is not a single instance in the book where a practical problem is solved, using field theory, that has not already been solved. No new techniques are derived, no new solution obtained, and no unity of approach is established, the authors' intentions not withstanding. It is not unfair, this reviewer believes, to say that mathematics has gotten in the way. In this regard, field theory is not shown to be useful here.

This volume can be evaluated using other similar writings for comparison. An outstanding example of applied mathematics and luminous radiative transfer is $\mathrm{R}$. W. Presendorfer's RADIATIVE TRANSFER ON DISCRETE SPACES, (Pergamon Press).

Unlike the obscurity that maps much of the book, the first chapter is clear, purposeful, and helpful. It contains a description of the passage from physical optics to geometrical optics that is excellent. The rest of this volume is a curiosity.

\section{L, DILAURA}

